\title{
The decomposition of hydrogen peroxide by marine phytoplankton
}

\section{La décomposition du peroxyde d'hydrogène par le phytoplancton marin}

\author{
George T.F. Wong *, William M. Dunstan, Dong-Beom Kim \\ Department of Ocean, Earth and Atmospheric Sciences, Old Dominion University, Norfolk, VA 23529-2076, USA
}

Received 11 July 2002; revised and accepted 10 October 2002

\begin{abstract}
All nine species of marine phytoplankton tested (a cyanobacterium: Synechococcus sp., three diatoms: Chaetoceros simplex, Thalassiosira oceanica and Skeletonema costatum, two prymnesiophytes: Pleurochrysis carterae and Isochrysis galbana, a prasinophyte: Tetraselmis sp., a green alga: Dunaliella tertiolecta, and a dinoflagellate: Amphidinium carterae) were able to decompose hydrogen peroxide in the dark. Since these phytoplankton species can be found widely in a variety of marine sub-environments, this indicates that the dark decomposition of hydrogen peroxide by phytoplankton is a general phenomenon in the oceans. The decomposition rates were first order with respect to the concentration of hydrogen peroxide and biomass. The second-order rate constants for these nine species of phytoplankton ranged between $2 \times 10^{-4}$ and $2.7 \times 10^{-2} \mu \mathrm{g}$ Chl- $a^{-1} 1 \mathrm{~h}^{-1}$. Synechococcus sp. and $S$. costatum were the most efficient, while P. carterae and D. tertiolecta were the least efficient decomposers. While the magnitudes and patterns in the changes were species-dependent, in general, increasing salinity, temperature, the presence of light and the depletion of nutrients enhanced the decomposition of hydrogen peroxide. The effect of growth phase was small.
\end{abstract}

(c) 2003 Éditions scientifiques et médicales Elsevier SAS. All rights reserved.

\section{Résumé}

L'ensemble formé par cinq espèces océaniques (une cyanobactérie : Synechococcus sp.; deux diatomées : Chaetoceros simplex et Thalassiosira oceanica, et deux prymnésiophytes : Pleurochrysis carterae et Isochrysis galbana) et quatre espèces côtières (une prasinophyte : Tetraselmis sp.; une algue bleue : Dunaliella tertiolecta; une diatomée : Skeletonema costatum et un dinoflagellé : Amphidinium carterae) de phytoplancton testées sont capables de décomposer le peroxyde d'hydrogène à l'obscurité. Ces espèces sont ubiquistes, ce qui montre que la décomposition à l'obscurité du peroxyde d'hydrogène est un phénomène répandu. Les taux de décomposition vont de $2,0 \times 10^{-4}$ et $2,7 \times 10^{-2} \mu \mathrm{g}$ Chl- $a^{-1} 1 \mathrm{~h}^{-1}$. Synechococcus sp. et $S$. costatum sont les décomposeurs les plus efficaces tandis que $P$. carterae et $D$. tertiolecta le sont le moins. L'aptitude à la décomposition du peroxyde d'hydrogène est affectée par les modifications physiques et chimiques de l'environnement et des facteurs biologiques. Un accroissement de la salinité et de la température, la présence de lumière et l'épuisement des sels nutritifs rehausse cette décomposition. L'effet de la phase de croissance est léger. L'importance et la nature de ces changements en fonction des modifications de l'environnement varie d'une espèce à l'autre.

(C) 2003 Éditions scientifiques et médicales Elsevier SAS. Tous droits réservés.

Keywords: Marine phytoplankton; Hydrogen peroxide; Oxidation-reduction

Mots clés : Phytoplancton marin ; Peroxyde d'hydrogène ; Oxydo-réduction

* Corresponding author

E-mail address: gwong @odu.edu (G.T.F. Wong). 


\section{Introduction}

Hydrogen peroxide is a reactive transient that can be found rather ubiquitously in the surface waters of the oceans at concentrations of $10^{1}-10^{2} \mathrm{nM}$ (Zika et al., 1985; Palenik and Morel, 1988; Johnson et al., 1989; Weller and Schrems, 1993; Moore et al., 1993; Petasne and Zika, 1997; Hanson et al., 2001). The sources of hydrogen peroxide in the marine environment are reasonably well documented. The major ones are in situ photochemical production (Cooper and Zika, 1983; Cooper et al., 1988; Wong and Wong, 2001), atmospheric deposition (Zika et al., 1982; Cooper et al., 1987; Hanson et al., 2001) and biological production (Palenik and Morel, 1988). Among these three, in situ photochemical production is the most dominant overall source. There must also be corresponding sinks, as elevated concentrations of hydrogen peroxide can have deleterious effects on biological systems. For example, at sufficiently high concentrations, hydrogen peroxide can cause damage to cell membranes, mutagenesis and the bleaching of chlorophyll (Ananthaswamy and Einstark, 1976; McCormick et al., 1976; Dixit et al., 1982; Lawlor, 1987). Even at its natural concentrations, hydrogen peroxide can still affect the marine ecosystem indirectly by modifying the speciation of trace elements. Through the peroxide-oxygen and peroxide-water half reactions, hydrogen peroxide possesses both oxidizing and reducing properties. In general, it acts as an oxidizing agent under acidic conditions and as a reducing agent under basic conditions. Under the mildly basic condition of seawater, it can behave in both fashions (Zafiriou,1983; Zafiriou et al., 1984; Moffett and Zafiriou, 1990). In the process, it affects the redox speciation of a number of ecologically important trace elements, including iron (Moffett and Zika, 1987; Millero and Sotolongo, 1989; King and Farlow, 2000), copper (Moffett and Zika, 1987; Sharma and Millero, 1989; Millero et al., 1991), chromium (Pettine and Millero, 1990; Pettine et al., 1991) and arsenic (Pettine and Millero, 2000). The speciation of these trace elements affects their biological availability and/or toxicity and, thus, their influence on the behavior of the marine ecosystem.

The sinks of hydrogen peroxide in the oceans have not been as well studied as its sources. The contribution from its chemical auto-decomposition is minimal to negligible (Szymszak and Waite, 1988; Cooper et al., 1994). The contribution from a photochemical decomposition is larger than that from auto-decomposition, but it is still insufficient to account for the decomposition rates observed in natural waters (Moffett and Zafiriou, 1990). The major sink of hydrogen peroxide has long been suspected to be its biologically mediated decomposition (Cooper and Zepp, 1990; Cooper et al., 1994); Moffett and Zafiriou (1990) reported that almost all the decomposition of hydrogen peroxide in the Vineyard Sound could be attributed to the enzymatic activities of catalase and peroxidase. Less is known about the exact organisms that are responsible for the reaction. In fresh water, several algae have been shown to have the ability to induce the decomposition of hydrogen peroxide (Zepp et al., 1987). Recently, Petasne and Zika (1997) reported that, qualitatively, six species of marine phytoplankton and one marine bacterium also possess the ability to decompose hydrogen peroxide to varying degrees. Here, we report a more comprehensive and quantitative study on the ability of nine phylogenetically diverse species of marine phytoplankton, including both oceanic and coastal species, to decompose hydrogen peroxide and how the process may be affected by environmental conditions.

\section{Materials and methods}

\subsection{Phytoplankton cultures}

Nine species, representing seven major phylogenetic groups, of phytoplankton were used as test organisms Table 1). Five of these species were isolated from the oceanic environment (a cyanobacterium, Synechococcus sp. (CCMP 1334), two diatoms, Chaetoceros simplex (CCMP 199) and Thalassiosira oceanica (CCMP 1005), and two prymnesiophytes, Pleurochrysis carterae (CCMP 649) and Isochrysis galbana (CCMP 1323)). The remaining four were representative of near-shore species (a prasinophyte, Tetraselmis sp. (CCMP 896), a green alga, Dunaliella tertiolecta (CCMP 1320), a diatom, Skeletonema costatum (CCMP 1332), and a dinoflagellate, Amphidinium carterae (CCMP 1314)). Axenic cultures of these phytoplankton species were obtained from the Provasoli-Guillard Center for Culture of Marine Phytoplankton, Bigelow Laboratory, Boothbay Harbor, ME, USA. Stock cultures were maintained in an $f / 2$ medium (Guillard and Ryther, 1962) at $23{ }^{\circ} \mathrm{C}$ under a 12:12-h light/dark cycle at a photosynthetically active radiation of approximately $75 \mu \mathrm{E} \mathrm{m}^{-2} \mathrm{~s}^{-1}$. The medium was

Table 1

Specific decomposition rate constants in the decomposition of hydrogen peroxide by marine phytoplankton

\begin{tabular}{lll}
\hline Species & Habitat & $\begin{array}{l}\text { Specific decomposition } \\
\text { rate constant, } \mathrm{k}_{\mathrm{d}} \\
\left(\mu \mathrm{g} C \mathrm{Ch}-\mathrm{a}^{-1} 1 \mathrm{~h}^{-1}\right)\end{array}$ \\
\hline $\begin{array}{l}\text { Cyanophyceae (cyanobacteria) } \\
\text { Synechococcus sp. }\end{array}$ & Oceanic & $2.7 \times 10^{-2}$ \\
$\begin{array}{l}\text { Bacillariophyceae (diatoms) } \\
\text { S. costatum }\end{array}$ & Coastal & $2.3 \times 10^{-2}$ \\
$\begin{array}{l}\text { C. simplex } \\
\text { T. oceanica }\end{array}$ & Oceanic & $3.7 \times 10^{-3}$ \\
$\begin{array}{l}\text { Prasinophyceae } \\
\text { Tetraselmis sp. }\end{array}$ & Oceanic & \\
$\begin{array}{l}\text { Prymnesiophyceae } \\
\text { P. carterae }\end{array}$ & Coastal & $4.5 \times 10^{-3}$ \\
$\begin{array}{l}\text { I. galbana } \\
\text { Dinophyceae (dinoflagellates) } \\
\text { A. carterae }\end{array}$ & Oceanic & $4 \times 10^{-4}$ \\
$\begin{array}{l}\text { Chlorophyceae (green algae) } \\
\text { D. tertiolecta }\end{array}$ & Coastal & $0.9 \times 10^{-3}$ \\
\hline
\end{tabular}


prepared with Sargasso Sea surface water. The salinity of the medium was 30. Cells were harvested at the late log growth phase, as indicated by the in vivo fluorescence, for the experiments.

\subsection{Instruments and methods}

Prior to each experiment, an aliquot of a stock culture was first pre-conditioned in the dark for $2-3 \mathrm{~h}$ in the $f / 2$ medium. In order to minimize the initial background concentration of hydrogen peroxide, the cells were concentrated and washed twice with a fresh $f / 20$ medium before an aliquot was finally inoculated into the incubation bottle containing an $f / 20$ medium. (The slow centrifugation, decantation and resuspension employed in the washing cycles did not affect the growth of the phytoplankton. The cells could assimilate ${ }^{14} \mathrm{C}$ labeled bicarbonate equally well before and after a washing cycle.) In order to avoid any catalytic effect of trace metals on the chemical auto-decomposition of hydrogen peroxide, no trace metal was added to the $f / 20$ culture medium. The medium was prepared with surface Sargasso Sea water that had been filtered through an $\mathrm{A} / \mathrm{E}$ glass fiber filter and aged in the dark for 2 months so that any residual hydrogen peroxide would have decayed away. It was re-filtered through a $0.2 \mu \mathrm{m}$ Nuclepore filter just before use in order to remove any bacteria that might have been present. The residual concentration of hydrogen peroxide in the medium thus prepared could be maintained at below the detection limit of $5 \mathrm{nM}$. The incubation bottles were amber high density polyethylene bottles, and the experiments were conducted in a dimly lit room at $23{ }^{\circ} \mathrm{C}$. About $900 \mathrm{nM}$ of hydrogen peroxide were added to the culture. Then, sub-samples were drawn from the incubation bottle at the beginning of the incubation period for the determination of chlorophyll- $a$ and at regular time intervals for up to $8 \mathrm{~h}$ for the determination of hydrogen peroxide. In most cases, readily detectable concentration changes of over $100 \mathrm{nM}$ occurred within the first $3 \mathrm{~h}$ of incubation. The short durations of these experiments insured that the behavior of the organism reflected the conditions in which it was pre-conditioned before it was inoculated into the final f/20 incubation medium. The added hydrogen peroxide should not have altered the behavior of the organisms. The concentration used was within the range found in marine waters. Concentrations of at least up to $2000 \mathrm{nM}$ did not alter the growth curve, as indicated by changes in in vivo fluorescence, of Synechococcus sp. and S. costatum. In control experiments, cells killed with heat at $60^{\circ} \mathrm{C}$ and with poisons, using sodium azide and formaldehyde, were similarly incubated. Furthermore, filtrates of cell suspensions filtered through a $1 \mu \mathrm{m}$ filter, to remove the cells, and through a $0.45 \mu \mathrm{m}$ filter, to remove the cells and most bacteria, were similarly added to the culture medium and incubated in the presence of added hydrogen peroxide. There was no observable decomposition of hydrogen peroxide in any of the controls. This indicates that the decomposition of hydrogen peroxide in the cultures with living phytoplankton cells was caused by the presence of the phytoplankton alone.
Hydrogen peroxide was determined fluorometrically by the scopoletin-horseradish peroxidase (HRP) method (Holm et al., 1987; Zhang and Wong, 1999) by measuring the HRP-mediated bleaching of the fluorescence of scopoletin by hydrogen peroxide with a Perkin Elmer model 650-10S fluorescence spectrophotometer. The detection limit of the method was about $5 \mathrm{nM}$. The precision of the method was $\pm 5 \%$ or $\pm 5 \mathrm{nM}$, whichever was larger. For the determination of chlorophyll- $a$, an aliquot of the culture solution was filtered through a GF/F glass fiber filter. The cells retained on the filter were analyzed for chlorophyll- $a$ fluorometrically by the method of Strickland and Parsons (1972) by using a Turner Model 10-AU fluorometer.

\section{Results and discussion}

\subsection{Kinetics and species dependence of the dark production of hydrogen peroxide}

The concentration of hydrogen peroxide in the cultures of all nine species of phytoplankton tested decreased with time. Thus, all of them can mediate the decomposition of hydrogen peroxide. This suggests that the decomposition of hydrogen peroxide by marine phytoplankton is a common phenomenon. The time courses of change of the concentration of hydrogen peroxide in the cultures of Synechococcus sp. and S. costatum are shown in Fig. 1. The concentration of hydrogen peroxide decreased exponentially with time. Two primary factors that govern the rate of decomposition are the concentration of hydrogen peroxide and the biomass. The decomposition of hydrogen peroxide by $S$. costatum and Synechococcus sp. was followed at different concentrations

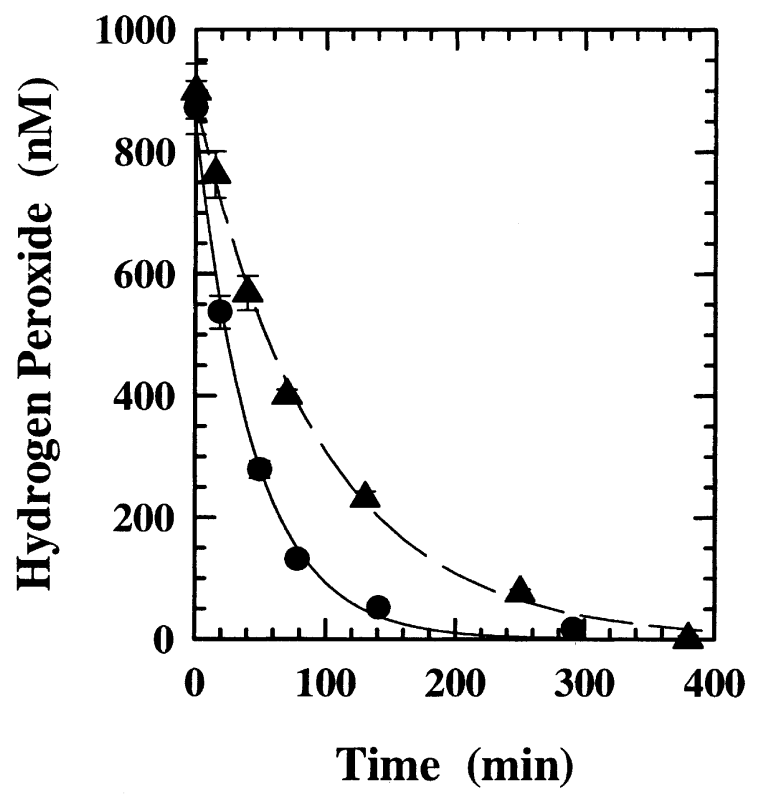

Fig. 1. The time courses of change in the concentration of hydrogen peroxide in cultures of $S$. costatum $(\boldsymbol{\Delta},----)$ and Synechococcus sp. $(\bullet,-)$. Lines represent model-generated relationships. 


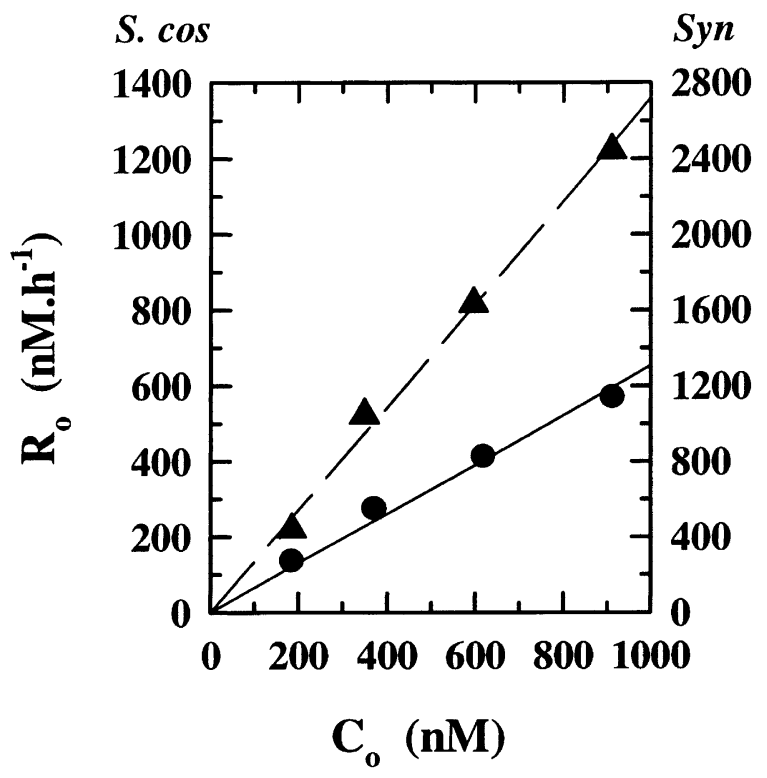

Fig. 2. The effect of the initial concentration of hydrogen peroxide on the decomposition of hydrogen peroxide by $S$. costatum $(\boldsymbol{\Lambda},----$, left scale) and Synechococcus sp. $(\bullet, \ldots$, right scale) at a fixed concentration of chlorophyll- $a$. The lines are the best fit lines. Initial decomposition rate decomposition rate during the first 30 min of incubation.

of added hydrogen peroxide at a fixed concentration of chlorophyll- $a$. The relationships between the initial decomposition rate during the first $30 \mathrm{~min}$ of incubation, $R_{0}$ in $\mathrm{nM} \mathrm{h}^{-1}$, and the initial concentration of hydrogen peroxide, $C_{0}$ in $\mathrm{nM}$, are shown in Fig. 2. In both cases, they were linearly related to each other with correlation coefficients, $r^{2}$, exceeding 0.98 . Thus, $\delta \mathrm{C} / \delta t \alpha C$, where $C$ is the concentration of hydrogen peroxide at time $t$.

The decomposition of hydrogen peroxide by these two phytoplankton was also followed at different biomasses, $\mathrm{M}$, as represented by the concentrations of chlorophyll- $a$ in $\mu \mathrm{g}$ Chl- $a 1^{-1}$, at a fixed initial concentration of hydrogen peroxide. At each concentration of chlorophyll- $a$, the time course of change in the concentration of hydrogen peroxide could be described by first-order kinetics so that

$$
-\delta \mathrm{C} / \delta \mathrm{t}=\mathrm{SC}
$$

where $\mathrm{S}$ is the first order total decomposition rate constant in $\mathrm{h}^{-1}$. Thus,

$$
\ln \left(\mathrm{C} / \mathrm{C}_{0}\right)=-\mathrm{St}
$$

where $C_{0}$ is again the initial concentrations of hydrogen peroxide. $S$ was estimated from a linearly least square fit of $\ln \left(C / C_{0}\right)$ versus $t$. For both $S$. costatum and Synechococcus sp., $S$ was linearly related to $M$ (Fig. 3) with correlation coefficients of 1.00. Thus, $\alpha C / \alpha t \alpha M$. Zepp et al. (1987) reported that the decomposition of hydrogen peroxide by freshwater algae follows second-order kinetics overall, first order with respect to the concentration of hydrogen peroxide and first order with respect to algal biomass. The marine

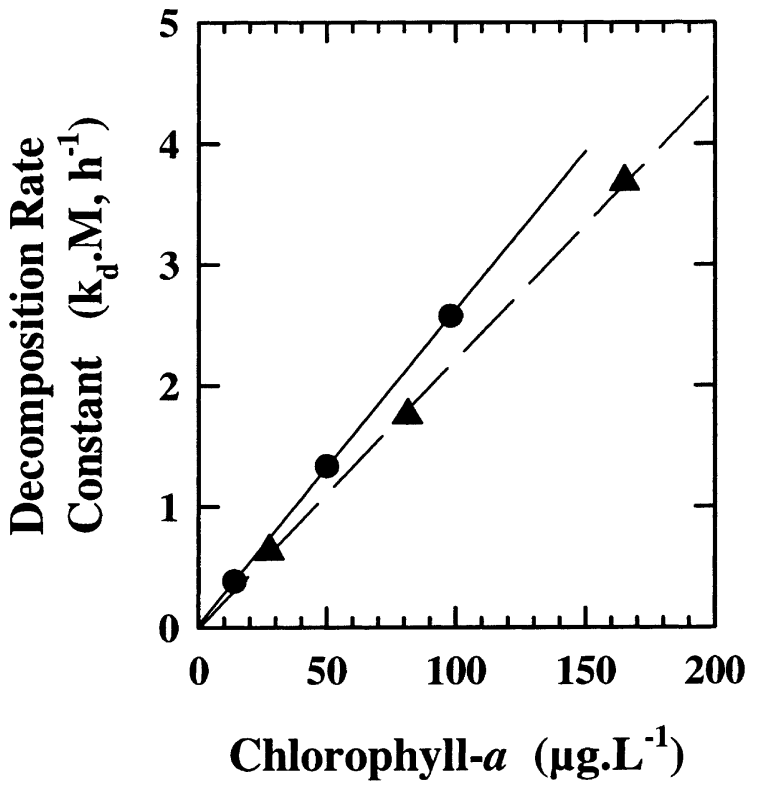

Fig. 3. The effect of biomass, as chlorophyll- $a$, on the decomposition of hydrogen peroxide by $S$. costatum $(\boldsymbol{\Lambda},---)$ and Synechococcus sp. $(\bullet,-)$ at a fixed initial concentration of hydrogen peroxide. Decomposition rate constant - first-order decomposition rate constant irrespective of the concentration of chlorophyll- $a$. $\mathrm{k}_{\mathrm{d}}$, specific decomposition rate constant in $\mu \mathrm{g}$ Chl$a^{-1} 1 \mathrm{~h}^{-1} . M$, biomass as chlorophyll- $a$ in $\mu \mathrm{g}^{-1}$. The lines represent the best fit lines.

phytoplankton followed the same trend, so that the complete rate law for the time course of change in the concentration of hydrogen peroxide can be given as:

$$
-\delta \mathrm{C} / \delta \mathrm{t}=\mathrm{k}_{\mathrm{d}} \mathrm{MC}
$$

where $\mathrm{k}_{\mathrm{d}}$ is the specific decomposition rate constant for a unit biomass in $\mathrm{L} \mathrm{g} \mathrm{Chl-} a^{-1} 1 \mathrm{~h}^{-1}$. Thus,

$$
\mathrm{S}=-\mathrm{k}_{\mathrm{d}} \quad \mathrm{M}, \quad \text { or } \quad \mathrm{k}_{\mathrm{d}}=-\mathrm{S} / \mathrm{M}
$$

The time courses of change of the concentration of hydrogen peroxide generated from this model in the cultures of Synechococcus sp. and S. costatum are also shown in Fig. 1 They can account for the observed changes in concentration well, as the deviations of the model-generated values from the observed values fell mostly within the analytical uncertainties. The relationships between $\ln \left(C / C_{0}\right)$ and $t$ for all nine species of phytoplankton tested and the best fit lines for each of these relationships are shown in Fig. 4. The correlation coefficients of all these relationships were higher than 0.98 . The specific decomposition rate constants estimated from these relationships are listed in Table 1] Their values stretched over two orders of magnitude, ranging from $10^{-4}$ to $10^{-2} \mu \mathrm{g} \mathrm{Chl}-a^{-1} 1 \mathrm{~h}^{-1}$. From this range of values of the specific decomposition rate constant, these nine species of phytoplankton may be subdivided into three groups, with specific decomposition rate constants that were about one order of magnitude apart. Synechococcus $\mathrm{sp}$. and S. costatum were the most efficient decomposers, with $\mathrm{k}_{\mathrm{d}}$ exceeding $1 \times 10^{-2} \mu \mathrm{g} \mathrm{Chl}-a^{-1} 1 \mathrm{~h}^{-1}$. The specific decomposition rate constants of five of the remaining seven phytoplankton species, namely, Tetraselmis sp., C. simplex, I. galbana, T. oce- 
(a)

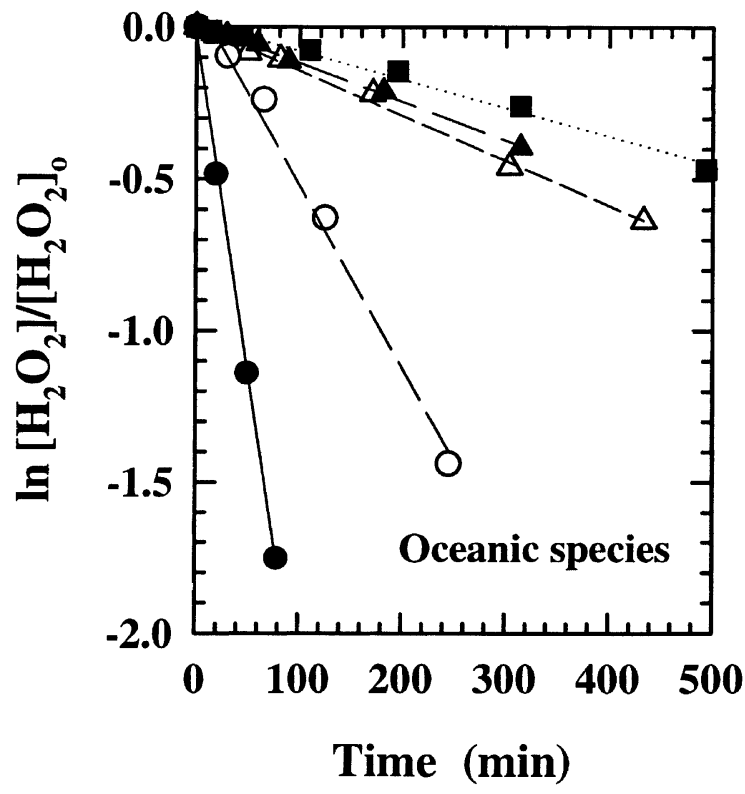

(b)

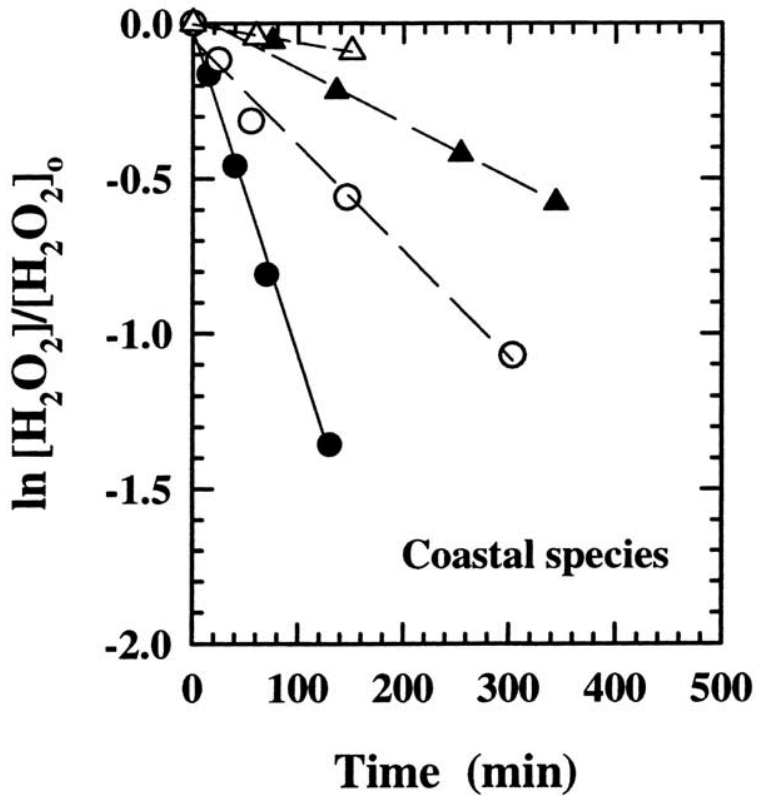

Fig. 4. The first-order relationships in the time courses of change in the concentration of hydrogen peroxide in cultures of (a) oceanic species Synechococcus sp. $(\bullet)$, C. simplex $(\mathrm{o})$, T. oceanica $(\mathbf{\Delta})$, I. galbana $(\triangle)$ and P. carterae ( $\square$ ), and (b) coastal species $S$. costatum $(\bullet)$, Tetraselmis sp. (o), A. carterae $(\boldsymbol{\Delta})$ and $D$. tertiolecta $(\triangle)$ at various biomasses. $\left[\mathrm{H}_{2} \mathrm{O}_{2}\right]$ and $\left[\mathrm{H}_{2} \mathrm{O}_{2}\right]_{0}$ are the concentration of hydrogen peroxide at any time $\mathrm{t}$ and at time zero, respectively. The lines represent the results from linear least square fit of the results from each species of phytoplankton.

anica and $A$. carterae, bunched within a narrow range of $1 \times 10^{-3}$ to $4 \times 10^{-3} \mu \mathrm{g}$ Chl- $a^{-1} 1 \mathrm{~h}^{-1}$. They were the moderately efficient decomposers. For the remaining two species, $P$. carterae and $D$. tertiolecta, the specific decomposition rate constants were less than $5 \times 10^{-4} \mu \mathrm{g} \mathrm{Chl}-a^{-1} 1 \mathrm{~h}^{-1}$. They were the least efficient decomposers. Petasne and Zika
(1997) also found that Synechococcus sp., with a rate constant of $3.51 \times 10^{10}$ cell $\mathrm{l}^{-1} \mathrm{~h}^{-1}$, was the most efficient decomposer among the six species of marine phytoplankton that they tested. Kana and Glibert (1987) reported that the concentration of chlorophyll-a in Synechococcus sp. varies with light intensity within the range of $1-5 \times 10^{-9} \mu \mathrm{g}$ Chl- $a^{-1}$ $1 \mathrm{~h}$. At these concentrations of chlorophyll- $a$ in the cells, the rate constant reported by Petasne and Zika (1997) corresponded to a specific decomposition rate constant of $10^{-1} \mu \mathrm{g}$ Chl- $a^{-1} 1 \mathrm{~h}^{-1}$. Considering the differences in the exact experimental conditions and set up and the possible natural biological variabilities, the agreement between this study and theirs was quite reasonable. Both oceanic and coastal species were represented in all three groups of decomposers Table 1. Thus, the decomposition of hydrogen peroxide by phytoplankton was neither confined to nor preferred in either one of these two marine sub-environments. Using values of the specific decomposition rate constant of $5 \times 10^{-4}$ to $10^{-2} \mu \mathrm{g} \mathrm{Chl-} a^{-1} 1 \mathrm{~h}^{-1}$, at typical concentrations of chlorophyll- $a$ of 0.5 and $5 \mu \mathrm{g}^{-1}$, respectively, in the open oceanic and the coastal environments, the half-lives of hydrogen peroxide in these two sub-environments can be estimated to be 140-2800 and 14-280 h, respectively. Based on direct field observations, Petasne and Zika (1997) reported halflives of $120 \mathrm{~h}$ in the oligotrophic Gulf Stream and 30-110 h in coastal waters. The estimated values could account for the observed values in the coastal waters quite well. In the oligotrophic waters, the observed value was at the lower end of the estimated range. In the laboratory experiments, the cells were pre-conditioned in an f/20 medium, and the concentrations of the nutrients in such a medium were still orders of magnitude higher than those found in oligotrophic waters. Thus, these results might not have been fully representative of the situation in oligotrophic waters. All three species of diatom tested, including both oceanic and coastal species, were either the most efficient or moderately efficient decomposers. Nonetheless, the number of species tested within each phylogenetic group was still too limited to define groupings along this line.

\subsection{Effects of physical environmental conditions-salinity, temperature and light intensity}

The decomposition of hydrogen peroxide by $S$. costatum was followed at salinities of 25, 30 and 35 . The specific decomposition rate constant increased with increasing salinity (data not shown). The total increase in this salinity range was about a factor of four. The effects of temperature were followed in cultures of Synechococcus sp. and S. costatum between 5 and $33{ }^{\circ} \mathrm{C}$. The specific decomposition rate constant of Synechococcus sp. increased monotonically with increasing temperature Fig. 5. The relationship between the rate constant and temperature can be described by the following equation:

$$
\log \mathrm{k}_{\mathrm{d}}=6.38( \pm 0.08)-2359( \pm 318) / \mathrm{T}
$$




\section{1/Temperature $\left({ }^{0} K^{-1}\right)$}

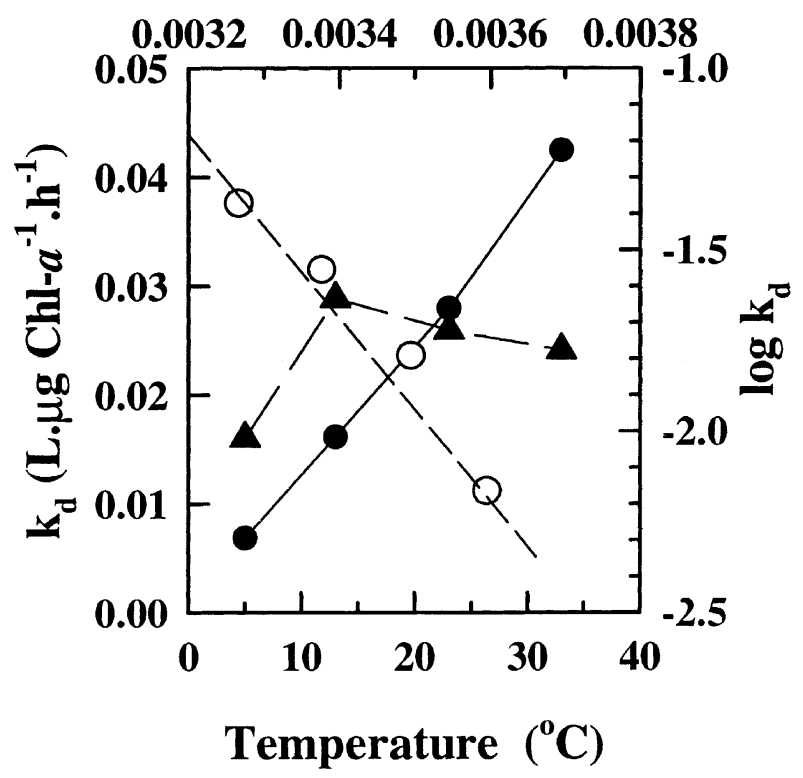

Fig. 5. The effect of temperature on the decomposition of hydrogen peroxide by $S$. costatum $(\boldsymbol{\Lambda},----)$ and Synechococcus sp. $(\bullet,-)$ and the relationship between $\log \mathrm{k}_{\mathrm{d}}$ and the reciprocal of temperature for Synechococcus $\mathrm{sp}$. $\left(\mathrm{o}, \ldots . .\right.$. , best fit line). $\mathrm{k}_{\mathrm{d}}$, specific decomposition rate constant.

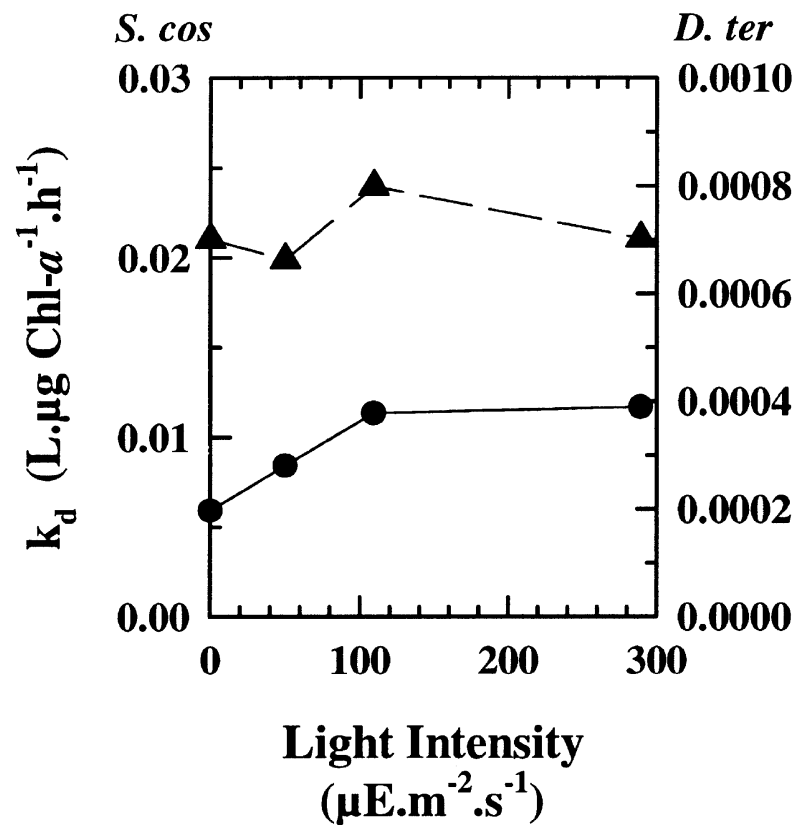

Fig. 6. The effect of light intensity on the decomposition of hydrogen peroxide by $S$. costatum $(\boldsymbol{\Lambda}$, ---- left scale) and D. tertiolecta $(\bullet,-$, , right scale). $\mathrm{k}_{\mathrm{d}}$ - specific decomposition rate constant.

where $\mathrm{T}$ is temperature in Kelvin Fig. 6. The rate constant was approximately doubled for every increase of $10^{\circ} \mathrm{C}$. The corresponding activation energy for the decomposition of hydrogen peroxide was $10.8( \pm 1.5) \mathrm{kcal} \mathrm{mol}^{-1}$. For $S$. costatum, the specific decomposition rate constant doubled from 5 to $13{ }^{\circ} \mathrm{C}$ and then stayed about constant at the higher temperatures Fig. 5p. Thus, both the magnitude and the pattern of these changes could vary from species to species.

The effects of light on the decomposition of hydrogen peroxide were tested in the cultures of $S$. costatum and $D$. tertiolecta. The specific decomposition rate constants were higher in the presence of light Fig. 6. The increase occurred primarily at low light intensities below $110 \mu \mathrm{E} \mathrm{m}^{-2} \mathrm{~s}^{-1}$. At higher light intensities, the rate constants stayed approximately the same in D. tertiolecta and decreased slightly in $S$. costatum. These decomposition rate constants were minimum rates, since the photochemically induced production of hydrogen peroxide would have occurred simultaneously in the presence of light. As the production rate is directly proportional to light intensity (Wong and Wong, 2001), its effect would have increased with increasing light intensity and led to the constant to even lower decomposition rates at the higher light intensities.

\subsection{Effects of biological factor and chemical environmental condition-nutrient condition and growth phase}

To test the effects of nutrient condition on the decomposition of hydrogen peroxide by Synechococcus sp., cells harvested at late $\log$ phase were first pre-conditioned in $f / 2, f / 20$ and $f / 100$ media before they were inoculated into the final $f / 20$ culture medium and incubated in the presence of added hydrogen peroxide. The specific decomposition rate constant increased about twofold when the nutrient concentrations decreased 10-fold from the $f / 2$ level to the $f / 20$ level (data not shown). There was no clear evidence of further increase in the rate constant as the nutrient concentrations were further decreased by a factor of five to the $f / 100$ level.

Cells of Synechococcus sp. were harvested at the late log, the early senescent, the mid-senescent and the late senescent

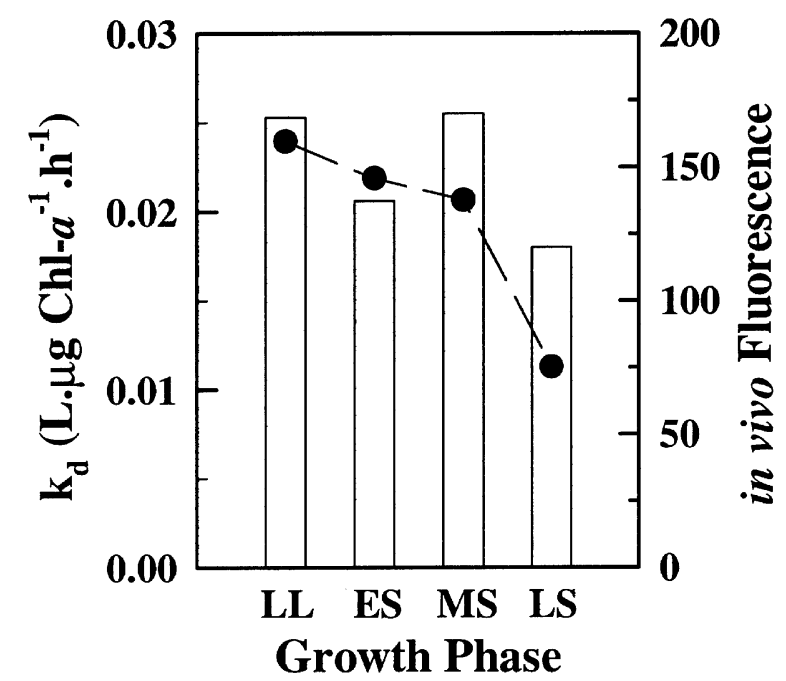

Fig. 7. The effect of growth phase on the decomposition of hydrogen peroxide by Synechococcus $\mathrm{sp}$. $\mathrm{k}_{\mathrm{d}}$, specific decomposition rate constant (hollow bars); $\bullet$, in vivo fluorescence; LL, late log phase; ES, early senescent phase; MS, mid-senescent phase; LS, late senescent phase. 
phases, as defined by the in vivo fluorescence of the culture, and then inoculated into an $f / 20$ medium in the presence of added hydrogen peroxide. The time courses of change in the concentrations of hydrogen peroxide in these cultures were then followed, and the specific decomposition rate constants were estimated. The results are shown in Fig. 7 The in vivo fluorescence decreased gradually from the late log phase to the mid-senescent phase before it dropped off more abruptly from the mid- to the late senescent phase. The corresponding change in the specific decomposition rate constant, bouncing between 0.018 and $0.025 \mu \mathrm{g} \mathrm{Chl}-a^{-1} 1 \mathrm{~h}^{-1}$, was relatively small. There was a suggestion that the decomposition rate constant was smaller in the late senescent phase, but the trend was not strong. Thus, the effect of the growth phase of the cells on the decomposition of hydrogen peroxide was small.

\section{Conclusion}

All five oceanic and four coastal species of marine phytoplankton tested could decompose hydrogen peroxide. The specific decomposition rate constants ranged from $10^{-4}$ to $10^{-2} \mu \mathrm{g} \mathrm{Chl-a^{-1 }} 1 \mathrm{~h}^{-1}$. Synechococcus sp. and S. costatum were the most efficient decomposers. Both oceanic and coastal species could be found among the most efficient, the moderately efficient and the least efficient decomposers. Thus, the decomposition of hydrogen peroxide is a widespread phenomenon in the oceans, and it is not confined to or preferred in either the oceanic or the coastal environment. The residence times of hydrogen peroxide in coastal waters estimated from these decomposition rate constants are consistent with those observed in the field. Increased salinity, temperature, the presence of light and the depletion of nutrients could all enhance the decomposition of hydrogen peroxide. The effect of growth phase was small. The magnitude and pattern of these changes were species-specific.

\section{Acknowledgements}

This work was supported in part by the National Science Foundation under grants number OCE-9301298 and INT9515521 to G.T.F. Wong and by the National Science of Council of Taiwan when this manuscript was prepared while G.T.F. Wong occupied a research chair at the National Center for Ocean Research of the National Science Council of Taiwan. This is NCOR contribution No. 63.

\section{References}

Ananthaswamy, H.N., Einstark, A., 1976. Near-UV-induced breaks in phage DNA: sensitization by hydrogen peroxide (a tryptophan photoproduct. Photochem. Photobiol. 24, 439-442.

Cooper, W.J., Zepp, R.G., 1990. Hydrogen peroxide decay in waters with suspended soils: evidence for biologically mediated processes. Can. J. Fish. Aquat. Sci. 47, 888-893.
Cooper, W.J., Zika, R.G., 1983. Photochemical formation of hydrogen peroxide in surface and ground waters exposed to sunlight. Science 220, 711-712.

Cooper, W.J., Saltzman, E.S., Zika, R.G., 1987. The contribution of rainwater to variability in surface water hydrogen peroxide. J. Geophys. Res. 92, 2970-2980.

Cooper, W.J., Zika, R.G., Petasne, R.G., Plane, J.M.C., 1988. Photochemical formation of $\mathrm{H}_{2} \mathrm{O}_{2}$ in natural waters exposed to sunlight. Environ. Sci. Technol. 22, 1156-1160.

Cooper, W.J., Shao, C., Lean, D.R.S., Gordon, A.S., Scully Jr, S.E., 1994. Factors affecting the distribution of $\mathrm{H}_{2} \mathrm{O}_{2}$ in surface waters. In: Baker, L.A. (Ed.), Environmental Chemistry of Lakes and Reservoirs. American Chemical Society Advances in Chemistry, Series No. 237. American Chemical Society, Washington, DC, pp. 391-422.

Dixit, R., Mukhtar, H., Biskers, D., 1982. Evidence that lipid peroxidation in microsomal membranes of epidermis is associated with generation of hydrogen peroxide and singlet oxygen. Biochem. Biophys. Res. Commun 105,546

Guillard, R.R.L., Ryther, J.H., 1962. Studies in marine planktonic diatoms. I. Cyclotella nana and Detanula confervacea. Can. J. Microbiol. 8, 229-239.

Hanson, A.K., Tindale, N.W., Abdel-Moati, M.A.R., 2001. An Equatorial Pacific rain event: influence on the distribution of iron and hydrogen peroxide in surface waters. Mar. Chem. 75, 69-88.

Holm, T.R., George, G.K., Barcelona, M.J., 1987. Fluorometric determination of hydrogen peroxide in groundwater. Anal. Chem. 59, 582-586.

Johnson, K.S., Willason, S.W., Wiesenburg, D.A., Lohrenz, S.E., Arnone, R.A., 1989. Hydrogen peroxide in the western Mediterranean Sea: a tracer for vertical advection. Deep-Sea Res. 36, 241-254.

Kana, T.M., Glibert, P.M., 1987. Effect of irradiances up to $2000 \mu \mathrm{E} \mathrm{m}^{-2} \mathrm{~s}^{-1}$ on marine Synechococcus WH7803 - I. Growth, pigmentation, and cell composition. Deep-Sea Res. 34, 479-495.

King, D.W., Farlow, R., 2000. Role of carbonate speciation on the oxidation of $\mathrm{Fe}(\mathrm{II})$ by $\mathrm{H}_{2} \mathrm{O}_{2}$. Mar. Chem. 70, 201-209.

Lawlor, D.W., 1987. Photosynthesis: Metabolism, Control, and Physiology. Longman, New York $262 \mathrm{p}$.

McCormick, J.P., Fischer, J.R., Pachlatko, J.P., 1976. Characterization of a cell-lethal product from the photooxidation of tryptophan: hydrogen peroxide. Science 191, 468-469.

Millero, F.J., Sotolongo, S., 1989. The oxidation of Fe(II) with hydrogen peroxide in seawater. Geochim. Cosmochim. Acta 53, 1867-1873.

Millero, F.J., Sharma, V.K., Karn, B., 1991. The rate of reduction of copper (II) with hydrogen peroxide in seawater. Mar. Chem. 36, 71-83.

Moffett, J.W., Zafiriou, O.C., 1990. An investigation of hydrogen peroxide chemistry in surface waters of Vineyard Sound with $\mathrm{H}_{2}{ }^{18} \mathrm{O}_{2}$ and ${ }^{18} \mathrm{O}_{2}$. Limnol. Oceanogr. 35, 1221-1229.

Moffett, J.W., Zika, R.G., 1987. Reaction kinetics of hydrogen peroxide with copper and iron in seawater. Environ. Sci. Technol. 21, 804-809.

Moore, C.A., Farmer, C.T., Zika, R.G., 1993. Influence of the Orinoco River on hydrogen peroxide distribution and production in the eastern Caribbean. J. Geophys. Res. 98, 2289-2298.

Palenik, B.P., Morel, F.M.M., 1988. Dark production of $\mathrm{H}_{2} \mathrm{O}_{2}$ in the Sargasso Sea. Limnol. Oceanogr. 33, 1606-1611.

Petasne, R.G., Zika, R.G., 1997. Hydrogen peroxide lifetimes in south Florida coastal and offshore waters. Mar. Chem. 56, 215-225.

Pettine, M., Millero, F.J., 1990. Chromium speciation in seawater: the probable role of hydrogen peroxide. Limnol. Oceanogr. 35, 730-736.

Pettine, M., Millero, F.J., 2000. Effect of metals on the oxidation of As(III) with $\mathrm{H}_{2} \mathrm{O}_{2}$. Mar. Chem. 70, 223-234.

Pettine, M., Millero, F.J., La Noce, T., 1991. Chromium (III) interactions in seawater through its oxidation kinetics. Mar. Chem. 34, 29-46.

Sharma, V.K., Millero, F.J., 1989. The oxidation of $\mathrm{Cu}(\mathrm{I})$ with hydrogen peroxide in natural waters. Geochim. Cosmochim. Acta 53, 2269-2276.

Strickland, J.D.H., Parsons, T.R., 1972. A Practical Handbook of Seawater Analysis. second ed. Bulletin of the Fisheries Research Board, Canada, 167 Ottawa. 
Szymszak, R., Waite, T.D., 1988. Generation and decay of hydrogen peroxide in estuarine waters. Aust. J. Mar. Freshwater Res. 39, 289-299.

Weller, R., Schrems, O., 1993. $\mathrm{H}_{2} \mathrm{O}_{2}$ in the marine troposphere and seawater of the Atlantic Ocean. Geophys. Res. Lett. 20, 125-128.

Wong, A.Y.L., Wong, G.T.F., 2001. The effect of spectral composition on the photochemical production of hydrogen peroxide in lake water. Terres. Atmos. Ocean. Sci. 12, 695-704.

Zafiriou, O.C., 1983. Natural water photochemistry. second ed. In: Riley, J.P., Chester, R. (Eds.), Chemical Oceanography, vol. 8. Academic Press, London, pp. 339-379.

Zafiriou, O.C., Joussot-Dubien, J., Zepp, R.G., Zika, R.G., 1984. Photochemistry of natural waters. Environ. Sci. Technol. 18, 358A371A.
Zepp, R.G., Skurlatov, Y.I., Pierce, J.T., 1987. Algal-induced decay and formation of hydrogen peroxide in water: its possible role in oxidation of anilines by algae. In: Zika, R.G., Cooper, W.J. (Eds.), Photochemistry of Environmental Aquatic Systems. American Chemical Society Symposium, Series No. 327. American Chemical Society, Washington, DC, pp. 215-224.

Zhang, L.S., Wong, G.T.F., 1999. Optimal conditions and sample storage for the determination of $\mathrm{H}_{2} \mathrm{O}_{2}$ in marine waters by the scopoletin-HRP fluorometric method. Talanta 48, 1030-1038.

Zika, R.G., Saltzman, E., Chameides, W.L., Davis, D.D., 1982. $\mathrm{H}_{2} \mathrm{O}_{2}$ levels in rain water collected in South Florida and the Bahama Islands. J. Geophys. Res. 8, 5015-5017.

Zika, R.G., Moffett, J.W., Petasne, R.G., Cooper, W.J., Saltzman, E.S., 1985. Spatial and temporal variations of hydrogen peroxide in Gulf of Mexico waters. Geochim. Cosmochim. Acta 49, 1173-1184. 